\title{
Estimating Fatigue Related Damage in Alloys under Block-type Non-symmetrical Low-cycle Loading
}

Francesco dell'Isola, Ivan A. Volkov, Leonid A. Igumnov, Simon R. Eugster, Svetlana Yu. Litvinchuk, Dmitri A. Kazakov, Vasilii A. Gorohov \& Bilen Emek Abali

\begin{abstract}
Processes of plastic deformation and damage accumulation in polycrystalline structural alloys are investigated under block-type, nonstationary, nonsymmetric cyclic loading. In the framework of damage mechanics, a mathematical model is proposed that effectively describes elastoplastic deformation and fatigue related damage accumulation processes under low-cycle loading. This model can be subsumed under three main parts: the relations defining elastoplastic behavior of the material; the equations describing damage accumulation kinetics; the strength criterion of the damaged material. For validating the model, we perform a numerical analysis and a comparison with the data from full-scale experiments. We demonstrate that the proposed model qualitatively and quantitatively describes the main effects of plastic deformation and damage accumulation processes in structural alloys under complex loading scenarios. Moreover, fatigue related lifetime of the structure is accurately captured by this model as well.
\end{abstract}

Keywords: Low-cycle fatigue $\cdot$ Plasticity $\cdot$ Non-symmetric loading $\cdot$ Damage mechanics $\cdot$ Numerical analysis $\cdot$ Experiments

Francesco dell'Isola · Ivan A. Volkov · Leonid A. Igumnov · Svetlana Yu. Litvinchuk · Dmitri A. Kazakov · Vasilii A. Gorohov

Research Institute for Mechanics, National Research Lobachevsky State University of Nizhny Novgorod, Russian Federation,

e-mail: fdellisola@gmail.com,pmptmvgavt@yandex.ru,igumnov@mech.unn.ru,

litvinchuk@mech.unn.ru,kazakov@mech.unn.ru,vas-gor@rambler.ru

Simon R. Eugster

Institute for Nonlinear Mechanics, University of Stuttgart, Germany,

e-mail: simon-raphael.eugster@inm.uni-stuttgart.de

Bilen Emek Abali

Institute of Mechanics, Technische Universität Berlin, Germany,

e-mail: bilenemek@abali.org 


\subsection{Introduction}

Materials response under cyclic loading is an important parameter for estimating the reliability and service life of a structure. In $\mathrm{n}$ experiment, service life is measured as the number of cycles until failure under repeated loading cycles. This measure is used to compare various designs. In order to estimate the number of cycles until failure, we aim to develop an accurate numerical analysis, for example by using the finite element method (FEM) as demonstrated in Abali (2017b). For a successful computation, the characteristics of the inelastic deformation in hazardous zones requires the formulation of governing equations of thermal plasticity accounting realistic properties of materials as proposed in Mitenkov et al (2007).

Currently, special attention is given to experimental study of cyclic deformation processes since an experiment is of utmost importance to validate any model describing this complex phenomenon. A repetitive loading pattern causes a stationary cyclic deformation meaning that the same amount of energy dissipates in each cycle. Interestingly, it has been detected that preceded by a transition stage the energy dissipation in each cycle starts deviating from the mean value. We may say that there occurs a cyclic hardening, softening or relaxation in the response. We need parameters defining a plastic hysteresis loop.

In the process of non-symmetric cyclic deformation of the material, unilateral accumulation of plastic deformation may be observed. Under cyclic loading with initial anisotropy of the stress amplitude at half-cycles of tension and compression, relaxation is observed in average stresses up to zero in a finite number of loading cycles. Under a combined effect of mechanical and thermal loading, the process of cyclic variation generates a multiaxial and non-proportional response leading to additional effects in materials response. The results of an experimental investigation of such processes show that the behavior of structural materials under cyclic proportional loading substantially differ in the case of monotonous deformation processes-modeling a cyclic hardening has to be reconsidered. Analogously, multiaxial non-proportional cyclic processes substantially deviate from proportional cyclic processes as in Lemba (1978); Makdauel (1985); Ohasi et al (1985); Tanaka et al (1985a,b); Hassan et al (2008); Huang et al (2014); Jiang and Zhang (2008); Taleb et al (2014).

Governing equations are often developed on the basis of monotonous loading processes. They fail to model the specific features of cyclic deformation under both proportional and non-proportional loading phenomena. Hence, it is challenging to expect a good estimation of fatigue related damage by using these equations. We suggest to model materials response by evaluating service life characteristics of materials with the aid of experimental studies under proportional as well as nonproportional loading, see Bodner and Lindholm (1976); Lemaitre (1985); Chaboche (1989); Bondar and Danshin (2008); Volkov and Korotkikh (2008); Mitenkov et al (2015). Classical methods for predicting fatigue life of materials utilize semiempirical formulas based on the assumption that the energy dissipation remains constant through the service life. These methods not only require large bulks of 
experimental information, they also hold only for a small class of loading regimes within the limits of available basic experimental data as in Collins (1984).

A novel scientific approach is proposed to overcome the aforementioned difficulties, see Murakami (1983); Volkov and Igumnov (2017). This so-called mechanics of damaged materials (MDM) studies the processes of growth of microdefects, mechanical behavior of damaged materials by describing the effect of distributed microdefects, using certain mechanical parameters, and the formation of macroscopic cracks (processes of damage accumulation), trying to combine the viewpoints of materials science and continuum mechanics. The current practice of using this approach for various mechanisms of exhausting the service life allows us to state that such an approach is effective enough for the practical purposes of evaluating service life characteristics of materials and can accurately evaluate the process of exhausting the service life of structural elements and parts of load-carrying structures.

Ample studies consider novel developments in plasticity. Governing equations in coupled examples has been studied in several works, for example see Papadopoulos and Lu (1998); Miehe et al (2009); Soyarslan and Tekkaya (2010); Altenbach and Eremeyev (2014b); Abali (2017a). Especially models involving porosity as well as viscoelasticity is challenging, among others, see Altenbach and Eremeyev (2014a); Misra and Poorsolhjouy (2015); Placidi (2016). Complex phenomena and their numerical implementation in 3D depends on the success of the accurate modeling of the material behavior as presented in Papadopoulos and Lu (2001); Schröder et al (2002); Montáns and Bathe (2005); Mazière and Forest (2015); Eremeyev et al (2016); Giorgio et al (2016).

The present paper proposes a mathematical model of MDM describing processes of complex plastic deformation and damage accumulation in structural materials (metals and their alloys) under monotonous and cyclic proportional and non-proportional thermal-mechanical loading regimes. To assess the reliability and the scope of applicability of the developed defining relations of MDM, the processes of plastic deformation and fatigue damage accumulation in stainless steels (X10CrNiTi18-10, X10CrNiTi18-9) under block-type, nonstationary, non-symmetric, low-cycle loading were numerically analyzed. The obtained numerical results are compared with the data from full-scale experiments.

\subsection{Defining Relations of Mechanics of Damaged Media}

A model as in Volkov and Korotkikh (2008); Volkov and Igumnov (2017) describing the damage in a body consists of the following:

- relations defining the elastoplastic behavior of the material, accounting for its dependence on the failure process;

- evolutionary equations describing damage accumulation kinetics;

- a strength criterion of the damaged material. 


\subsubsection{Defining Relations in Plasticity}

The definition of relations modeling plasticity is based on the following assumptions:

- Components of strain tensors $e_{i j}$ and strain rates $e_{i j}$ include elastic, ${ }^{\mathrm{e}} e_{i j},{ }^{\mathrm{e}} e_{i j}{ }_{i j}$, and plastic strains, ${ }^{\mathrm{P}} e_{i j},{ }^{\mathrm{P}} e_{i j}{ }_{i j}$, in other words, the reversible and irreversible components.

- For various temperatures, the initial yield surface is described by a Mises type surface. The evolution of the yield surface is described by the variation of its radius ${ }^{\mathrm{P}} C$ and the motion of its center, so-called back stress, $\rho_{i j}$.

- The volume change is reversible, in other words, plastic deformation is deviatoric.

- Continuum body is isotropic at the reference frame; but anisotropy may be caused by plasticity.

For the elastic regime, the spherical and deviatoric parts of the stress and elastic strain tensors,

$$
\sigma_{i j}=\sigma \delta_{i j}+\sigma_{|i j|},{ }^{\mathrm{e}} e_{i j}=e \delta_{i j}+e_{|i j|},
$$

are modeled by Hooke's law with the DuhameL-Neumann extension as follows:

$$
\sigma=3 K\left({ }^{\mathrm{e}} e-\alpha\left(T-T_{\text {ref. }}\right)\right), \sigma_{|i j|}=2 G^{\mathrm{e}} e_{|i j|},
$$

with the material parameters, $K, \alpha, G$, depending on the temperature. Usually, the initial temperature of the simulation is assumed to be the reference temperature, $T_{\text {ref. }}$, in order to achieve the natural state initially. As a consequence, their rates read

$$
\sigma^{\cdot}=3 K\left({ }^{\mathrm{e}} e^{\cdot}-\alpha^{*} T-\alpha T^{\cdot}\right)+\frac{K^{\bullet}}{K} \sigma, \sigma_{|i j|}=2 G^{\mathrm{e}} e_{|i j|}+\frac{G^{\cdot}}{G} \sigma_{|i j|} .
$$

In classical or so-called PRANDTL-Reuss plasticity, a yield surface is introduced,

$$
F_{S}=S_{i j} S_{i j}-{ }^{\mathrm{P}} C, S_{i j}=\sigma_{|i j|}-\rho_{i j},
$$

by using an isotropic hardening with the center, ${ }^{\mathrm{P}} C$, and a kinematic hardening with its motion, $\rho_{i j}$. For modeling complex cyclic deformation modes in the stress space, we introduce the following yield surface:

$$
F_{\rho}=\rho_{i j} \rho_{i j}-\rho_{\max }^{2},
$$

providing a "memory" with the aid of the maximal modulus, $\rho_{\max }$. We consider such a temperature range, where annealing effects fail to be significant. Then the isotropic hardening, modeling the evolution of ${ }^{\mathrm{P}} C$, consists of three parts: effected by monotonous, cyclic, and temperature related phenomena. We follow Volkov and Korotkikh (2008); Mitenkov et al (2015) and implement the following evolution law: 


$$
\begin{aligned}
& { }^{\mathrm{p}} C \cdot=\left(q_{\chi} H(F \rho)+a\left(Q_{\mathrm{S}}-{ }^{\mathrm{p}} C\right) \Gamma\left(F_{\rho}\right)\right) \chi^{\bullet}+q_{3} T^{\bullet}, \\
& { }^{\mathrm{p}} C={ }^{\mathrm{p}} C^{0}+\int_{0}^{t}{ }^{\mathrm{p}} C \cdot \mathrm{d} t, \chi^{\cdot}=\sqrt{\frac{2}{3} \mathrm{p}_{i j}^{\cdot}{ }_{i j} e_{i j}}, \chi_{m}=\int_{0}^{t} \chi \cdot H\left(F_{\rho}\right) \mathrm{d} t, \chi=\int_{0}^{t} \chi^{\cdot} \mathrm{d} t, \\
& q_{\chi}=\frac{q_{2} A \psi_{1}+(1-A) q_{1}}{A \psi_{1}+(1-A)}, Q_{\mathrm{S}}=\frac{Q_{2} A \psi_{2}+(1-A) Q_{1}}{A \psi_{2}+(1-A)}, 0 \leq \psi \leq 1, i=1,2 \text {, } \\
& A=1-\cos ^{2} \theta, \cos \theta=n_{i j}^{e} n_{i j}^{s}, n_{i j}^{e}=\frac{e_{|i j|}}{\sqrt{e_{|i j|}^{e_{|i j|}}}}, n_{i j}^{s}=\frac{S_{i j}}{\sqrt{S_{i j} S_{i j}}}, \\
& \Gamma\left(F_{\rho}\right)=1-H\left(F_{\rho}\right), H\left(F_{\rho}\right)=\left\{\begin{array}{ll}
1, & F_{\rho}=0 \wedge \rho_{i j} \rho_{i j} \geq 0 \\
0, & F_{\rho}<0 \vee \rho_{i j} \rho_{i j}<0
\end{array},\right.
\end{aligned}
$$

where $q_{1}, q_{2}, q_{3}$ denote moduli of monotonous isotropic hardening; $Q_{1}, Q_{2}$ indicate moduli of cyclic isotropic hardening; $a$ is a constant defining evolution of the hysteresis loop of cyclic deformation; $Q_{\mathrm{S}}$ is the corresponding yield surface radius for the known $\rho_{\max }$ and $T ;{ }^{\mathrm{P}} C^{0}$ is the initial value of the yield surface radius. Evolution of the back-stress is obtained by introducing it as an internal variable and postulated to have the following form:

$$
\rho_{i j}^{\cdot}=f\left(\chi_{m}\right)\left(g_{1} \mathrm{p}_{i j}^{\cdot}-g_{2} \rho_{i j} \chi^{\cdot}\right)+g_{T} \rho_{i j}\left\langle T^{\cdot}\right\rangle+\tilde{\rho}_{i j}^{\cdot}, \rho_{i j}=\int_{0}^{t} \rho_{i j}^{\cdot} \mathrm{d} t,
$$

with

$$
\begin{aligned}
& f\left(\chi_{m}\right)=1+k_{1}\left(1-\exp \left(-k_{2} \chi_{m}\right)\right), \\
& \tilde{\rho}_{i j}^{\cdot}=g_{3}{ }^{\mathrm{p}} e_{i j}^{\cdot} H\left(F_{\rho}\right)-g_{4} \tilde{\rho}_{i j} \chi^{\bullet} \Gamma\left(F_{\rho}\right)\langle\cos (\gamma)\rangle \text {, } \\
& \langle\cos (\gamma)\rangle=\frac{\rho_{i j}^{\bullet} \tilde{\rho}_{i j}}{\sqrt{\rho_{k l}^{\cdot} \rho_{k l}^{*}} \sqrt{\tilde{\rho}_{m n} \tilde{\rho}_{m n}}},
\end{aligned}
$$

where $g_{1}, g_{2}, g_{3}, g_{4}, g_{T}$, as well as $k_{1}, k_{2}$ are material parameters to be determined experimentally.

Equations $(6.7)_{1,2}$ describe the anisotropic part of deformation hardening. Equation (6.7) $)_{3}$ models the evolution of $\rho_{i j}$ by including the effect of the temperature rate as well. Equation $(6.7)_{4}$ indicates an anisotropic hardening due to the unilaterally accumulated plastic deformation. Weighting factor $f\left(\chi_{m}\right)$ allows to describe the evolution of $\rho_{i j}$ under cyclic deformation regimes (Korotkikh, 1985). For a nonsymmetric cyclic loading, $\tilde{\rho}_{i j}$ models the cyclic plastic hysteresis loop differently for various loading strengths. In the case of vanishing $g_{T}=g_{3}=g_{4}=k_{1}=0$, Eqs. (6.7) reduce to the special case of Armstrong-Frederik-KadAshevich equations as follows:

$$
\rho_{i j}^{\cdot}=g_{1} \mathrm{p}_{i j}^{\cdot}-g_{2} \rho_{i j} \chi^{\cdot}
$$

In order to include a memory effect for the yield surface, it is necessary to generate an evolution equation for $\rho_{\max }$ as well,

$$
\rho_{\max }^{\cdot}=\frac{\rho_{i j} \rho_{i j}^{\cdot} H\left(F_{\rho}\right)}{\sqrt{\rho_{m n} \rho_{m n}}}-g_{2} \rho_{\max } \chi-g_{T} \rho_{\max }\left\langle T^{\cdot}\right\rangle .
$$


The plastic strain rate tensor components fulfill the orthogonality restriction at the yield surface

$$
{ }^{\mathrm{p}} e_{i j}=\lambda S_{i j},
$$

where $\lambda$ is proportionality coefficient determined from the condition that a new yield surface passes through the end of the stress deviator vector at the end of the loading stage.

As damage is modeled by a field function, $\omega$, we can easily introduce the effect of damage on the material properties by introducing effective stresses as in Volkov and Igumnov (2017),

$$
\begin{gathered}
\tilde{\sigma}_{|i j|}=F_{1}(\omega) \sigma_{|i j|}=\frac{G}{\tilde{G}} \sigma_{|i j|}=\frac{\sigma_{|i j|}}{(1-\omega)\left(1-\frac{6 K+12 G}{9 K+8 G}\right)}, \\
\tilde{\sigma}=F_{2}(\omega) \sigma=\frac{K}{\tilde{K}} \sigma=\frac{\sigma}{(1-\omega) \frac{4 G}{4 G+3 K \omega}},
\end{gathered}
$$

where $\tilde{G}, \tilde{K}$ are effective elastic moduli determined by the MackenzIE formulas (Mackenzie, 1950). Analogously, we propose to obtain

$$
\tilde{\rho}_{i j}=F_{1}(\omega) \rho_{i j} .
$$

\subsubsection{Evolutionary equations of fatigue damage accumulation}

Rate of damage is modeled by an evolution equation, for low-cycle fatigue (LCF), we define this relation by the following model as in Bodner and Lindholm (1976); Lemaitre (1985); Volkov and Korotkikh (2008); Volkov and Igumnov (2017):

$$
\omega^{\bullet}=f_{1}(\beta) f_{2}(\omega) f_{3}(W) f_{4}\left(W^{\bullet}\right),
$$

where the function $f_{1}(\beta)$ denotes the effects of volume change with $\beta=\sigma / \sigma_{\mathrm{u}}$, the function $f_{2}(\omega)$ incorporates the degree of the present damage accumulated over the time, the function $f_{3}(W)$ models the effect of the dissipated work (energy) on damage for creating a fracture, the function $f_{4}\left(W^{\cdot}\right)$ embodies the effects of the rate of damage energy. We model these functions in the following way:

$$
\begin{gathered}
f_{1}(\beta)=\exp (\beta), f_{2}(\omega)= \begin{cases}0, & W \leq W_{\mathrm{a}} \\
\omega^{1 / 3}(1-\omega)^{2 / 3} & W>W_{\mathrm{a}} \wedge \omega \leq \frac{1}{3} \\
\frac{16^{1 / 3}}{9} \omega^{-1 / 3}(1-\omega)^{-2 / 3} & W>W_{\mathrm{a}} \wedge \omega>\frac{1}{3}\end{cases} \\
f_{3}(W)=\frac{W-W_{\mathrm{a}}}{W_{\mathrm{f}}}, f_{4}\left(W^{\bullet}\right)=\frac{W^{\bullet}}{W_{\mathrm{f}}},
\end{gathered}
$$

where $\beta=\sigma / \sigma_{\mathrm{u}}$ gives the voluminosity of stressed state, $W_{\mathrm{a}}$ is the corresponding energy used for damage at the end of the stage of nucleation of microcracks under 
low cycle fatigue, and $W_{\mathrm{f}}$ is the energy used for macroscopic crack formation process. The duration of the microcracks nucleation phase will be related with the value of parameter $W_{\mathrm{a}}$. When microcracks reach the dimensions in the length scale of the mean distance between microcracks, the process of merging (agglomeration) starts. We circumvent introducing a detailed micromechanical model of this agglomeration and model this phenomenon via kinetic equation by introducing term $f_{2}(\omega)$ in such a way that relation $\omega^{*}=f_{1}(\omega)$ considers for the avalanche-like increase of the damage when damage reaches the value of $\omega=1 / 3$.

\subsubsection{Strength Criterion of the Damaged Material}

We implement a simple approach and terminate accumulation of microcracks in the case of damage approaching its critical value

$$
\omega=\omega_{\mathrm{f}},
$$

where this critical value has to be smaller than 1 , otherwise numerical instabilities occur. For engineering alloys $\omega_{\mathrm{f}}=0.3$ and for pure materials $\omega_{\mathrm{f}}=0.7$ (Lemaitre, 1985).

\subsection{Numerical Results}

Specimens of stainless steel $12 \mathrm{X} 18 \mathrm{H} 10 \mathrm{~T}$ were experimentally studied under a uniaxial tension-compression test at the ambient temperature in the Laboratory for Testing Physical-Mechanical Properties of Structural Materials, Research Institute for Mechanics, Nizhniy Novgorod Lobachevski State University. The testing procedure consisted of five subsequent tests including monotonous and cyclic loading as in Korotkikh (1985):

I. 20 cycles of symmetric cyclic loading with a deformation amplitude of $e_{11}=0.08 \%$

II. Monotonous tension up to the deformation of $e_{11}=5 \%$

III. 200 cycles of non-symmetric cyclic loading with the deformation amplitude of $\Delta e_{11}=1.2 \%$ and the mean deformation of $e_{11}^{(m)}=4.4 \%$ (during this test, plastic hysteresis loop occurs)

IV. Monotonous tension up to deformation $e_{11}=1 \%$

V. Non-symmetric cyclic loading with the deformation amplitude of $\Delta e_{11}=$ $1.2 \%$ and the mean deformation of $e_{11}^{(m)}=9.4 \%$ up to failure (the number of cycles to failure is $N_{f}=2800$, again, plastic hysteresis loop takes place)

We compile in Tables 6.1-6.3 the properties of the presented MDM model for steel X10CrNiTi18-10 determined from the results of experiments in Volkov and 
Table 6.1 Obtained parameters of the MDM model for X10CrNiTi18-10

\begin{tabular}{|c|c|c|c|c|c|c|c|c|}
\hline$K$ & $G$ & ${ }^{\mathrm{P}} C^{0}$ in $\mathrm{MPa}$ & $g_{1}$ in $\mathrm{MPa}$ & $g_{2}$ & $g_{3}$ in $\mathrm{MPa}$ & $g_{4}$ & $k_{1}$ & $k_{2} \quad a$ \\
\hline 165277 & 76282 & 203 & 20850 & 297 & 660 & 3 & 0.48 & 0.25 \\
\hline
\end{tabular}

Table 6.2 Modulus of cyclic hardening $Q_{\mathrm{S}}\left(\rho_{\max }\right)$ in MPa for X10CrNiTi18-10

$Q_{\mathrm{S}}$ in MPa 203210232232232232232

$\begin{array}{llllllll}\rho_{\max } \text { in } \mathrm{MPa} & 0 & 30 & 60 & 90 & 100 & 110 & 120\end{array}$

Table 6.3 Modulus of monotonous hardening $q_{\chi}$ in MPa for X10CrNiTi18-10

\begin{tabular}{lccccccccccccc}
\hline$q_{\chi}$ in MPa & -17000 & -4634 & -811 & 371 & 737 & 849 & 897 & 900 & 900 & 900 & 900 & 900 & 900 \\
\hline$\chi$ & 0 & 0.002 & 0.004 & 0.006 & 0.008 & 0.01 & 0.015 & 0.02 & 0.03 & 0.04 & 0.05 & 0.09 & 0.15 \\
\hline
\end{tabular}

Korotkikh (2008); Mitenkov et al (2015); Volkov and Igumnov (2017) and used for the following computations.

In order to present the results, we use dots for experiments and a continuous line for the computation in the following figures for the aforementioned 5 subsequent loading scenarios I-V demonstrated in Figs. 6.1-6.3

We emphasize the quantitative and qualitative agreement between the experimental data and its computation. Moreover, another set of experiments were conducted for stainless steel X10CrBiTi18-9 under non-stationary, non-symmetric cyclic loading as follows:

VI. The specimen is compressed up to $e_{11}=0.01$ and then in pulled in tensile up to $e_{11}=0.05$

VII. Non-symmetric cyclic loading is applied with a strain interval of $1 \%$ up to the failure, $N_{f}=850$. Plastic hysteresis loop occurs and after $500^{\text {th }}$ loading cycle, the loop becomes nearly symmetric.

Fig. 6.1 Comparison of the numerical results with the proposed model (continuous line) with the experimental data (dots). One single symmetric loading cycle as in I.

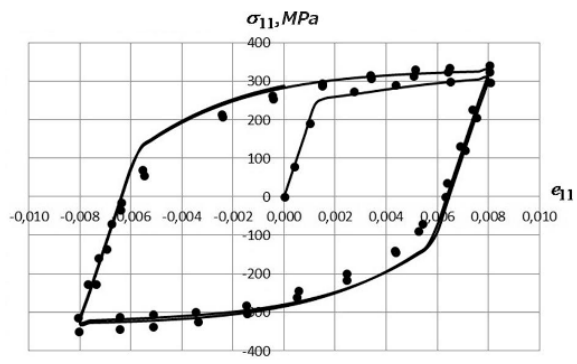



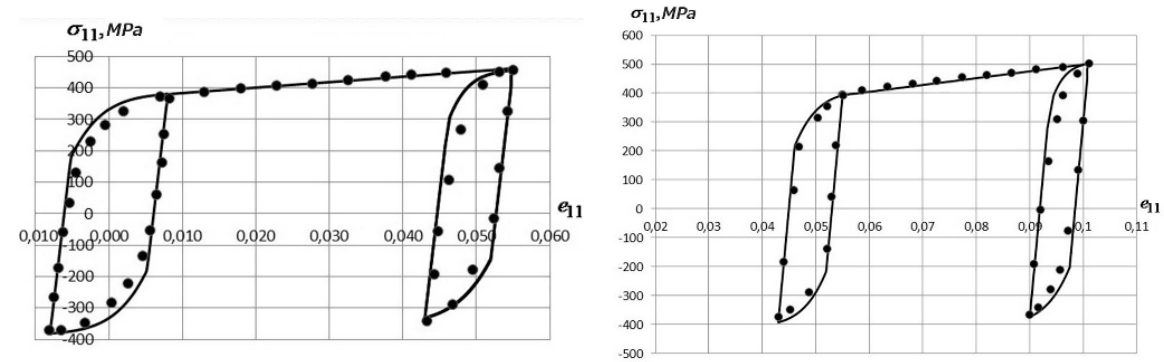

Fig. 6.2 Comparison of the numerical results with the proposed model (continuous line) with the experimental data (dots). Left: $20^{\text {th }}$ cycle of symmetric loading in II followed by a monotonous tensile test until $e_{11}=0.05$ and a subsequent non-symmetric cyclic loading. Right: $200^{\text {th }}$ cycle of III is followed by one cycle of V.
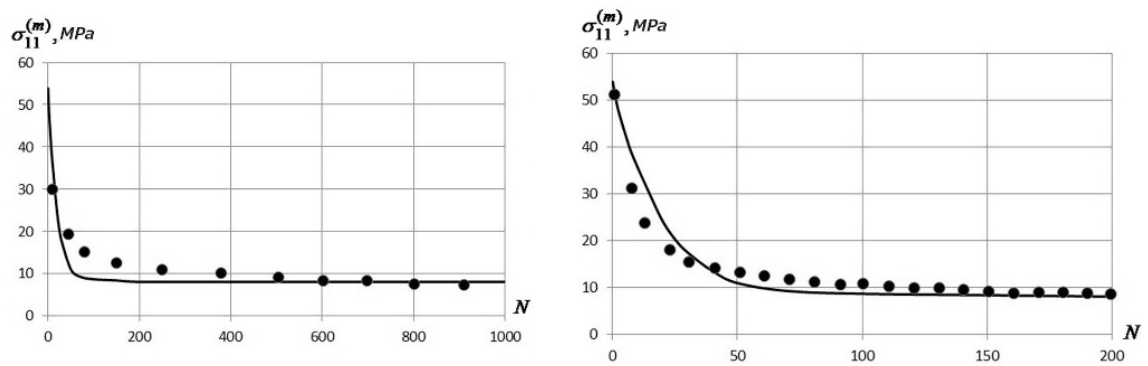

Fig. 6.3 Comparison of the numerical results with the proposed model (continuous line) with the experimental data (dots). The dissipated energy density given as the maximum stress amplitude by III (left) and V (right) loading scenarios.

Table 6.4 Obtained parameters of the MDM model for X10CrNiTi18-10

\begin{tabular}{cccccccccccc}
\hline$K$ & $G$ & ${ }^{\mathrm{P}} C^{0}$ in $\mathrm{MPa}$ & $g_{1}$ in $\mathrm{MPa}$ & $g_{2}$ & $g_{3}$ in $\mathrm{MPa}$ & $g_{4}$ & $k_{1}$ & $k_{2}$ & $a$ & $W_{a}$ & $W_{f}$ \\
\hline 165277 & 76282 & 190 & 24090 & 286 & 800 & 2 & 0.415 & 0.2 & 5 & 0 & 800 \\
\hline
\end{tabular}

Table 6.5 Modulus of cyclic hardening $Q_{\mathrm{S}}\left(\rho_{\max }\right)$ in MPa for X10CrNiTi18-9

$Q_{\mathrm{S}}$ in MPa 190205210215220225225

$\rho_{\max }$ in $\mathrm{MPa} \quad 0 \quad 20 \quad 40 \quad 60 \quad 80 \quad 100 \quad 120$

For calculations, we used the parameters as compiled in Tables 6.4-6.6 for the steel X10CrNiTi18-9 obtained from the results of experiment in Volkov and Korotkikh (2008); Mitenkov et al (2015). Analogously, the experiments VI-VII are utilized to validate the accuracy of the proposed model as demonstrated in Fig. 6.4. Two different models for the evolution equation show significant discrepancies in Fig. 6.4 


\begin{tabular}{lcccccccccccc}
\hline$q_{\chi}$ in MPa & -5000 & -4471 & -4188 & -3859 & -2460 & -182 & 888 & 1531 & 1274 & 913 & 913 & 913 \\
\hline$\chi$ & 0 & 0.002 & 0.004 & 0.006 & 0.008 & 0.01 & 0.015 & 0.02 & 0.03 & 0.04 & 0.05 & 0.06 \\
\hline
\end{tabular}
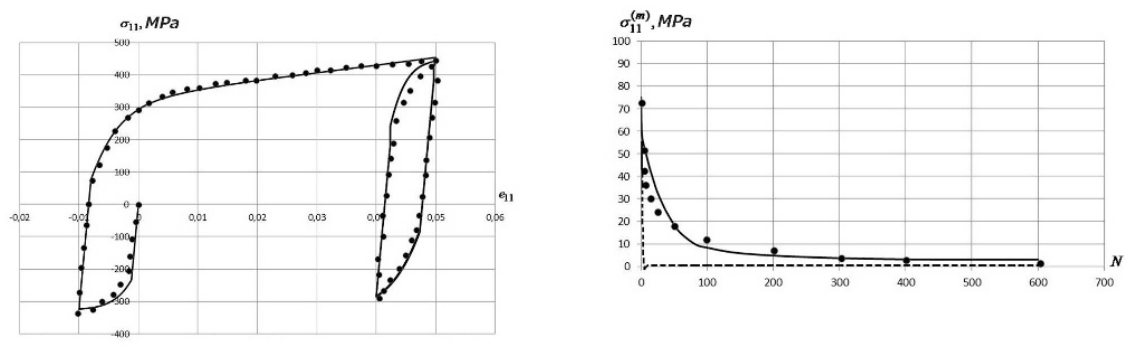

Fig. 6.4 Comparison of the numerical results with the proposed model (continuous line) with the experimental data (dots) for X10CrNiTi18-9. Left: at the $500^{\text {th }}$ cycle during the experiment VII. Right: mean stress for various cycles during the experiment VII, model in Eq. (6.7) 1 as the continuous line and model in Eq. (6.9) as the dash line.

Fig. 6.5 Comparison of the fatigue curves obtained by the two proposed models (dots and squares) with the experimental data (continuous line). Circles denote the thermal plasticity model with th evolution equation as in Eq. (6.7) $)_{1}$ and squares indicate the model with Eq. (6.9).

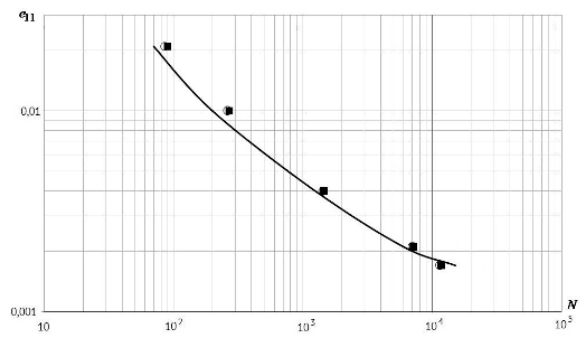

(right). By using the model in Eq. (6.9), we observe that cyclic hysteresis loop is immediately stated in the first loading cycle such that the physically-important relations of plasticity fail to be described accurately. By employing the model in Eq. (6.7), material behavior during the process is perfectly modeled. In Fig. 6.5, a fatigue curve is shown for the same material, X10CrNiTi18-9, experimented as in VII. The experimental data is quantitatively well represented by the numerical results acquired by the models in Eqs. (6.7), (6.9). In general, the comparison of the numerical and experimental results demonstrate the strength of the proposed MDM model. It describes the processes of fatigue life of polycrystalline structural alloys under non-symmetric low-cycle loading. 


\subsection{Conclusion}

A novel model has been proposed for modeling fatigue life of polycrystalline structural alloys under non-symmetric cyclic loading. The model is verified by utilizing experiments of block-type, transient, non-symmetric, low-cycle loading for two stainless steels (X10CrNiTi18-10, X10CrNiTi18-9). We have demonstrated that even different conditions are perfectly captured by this model, all material parameters are compiled in Tables 6.1-6.6. Two different versions have been implemented and their differences have been discussed. Fatigue life estimation is equally accurate in both versions for the case of non-symmetric low-cycle loading. We recommend to use the simpler version given in Eq. (6.9).

Acknowledgements This work was supported by a grant from the Government of the Russian Federation (contract No. 14.Y26.31.0031).

\section{References}

Abali BE (2017a) Computational Reality, Solving Nonlinear and Coupled Problems in Continuum Mechanics, Advanced Structured Materials, vol 55. Springer Nature, Singapore

Abali BE (2017b) Computational study for reliability improvement of a circuit board. Mechanics of Advanced Materials and Modern Processes 3(1):1-11

Altenbach H, Eremeyev V (2014a) Strain rate tensors and constitutive equations of inelastic micropolar materials. International Journal of Plasticity 63:3-17

Altenbach H, Eremeyev VA (2014b) Basic equations of continuum mechanics. In: Plasticity of Pressure-Sensitive Materials, Springer, pp 1-47

Bodner SR, Lindholm US (1976) Kriteriy prirasheniya povrezhdeniya dlya zavisyashego ot vremeni razrusheniya materialov (in Russian). Trudy Amer Ob-va inzh-meh Ser D Teoret Osnovy inzh Raschetov 100(2):51-58

Bondar VS, Danshin VV (2008) Plastichnost. proportsyonalnye i neproportsyonalalnye nagruzheniya (in Russian). M: Fizmatlit p 176

Chaboche JL (1989) Constitutive equations for cyclic plasticity and cyclic viscoplasticity. International journal of plasticity 5(3):247-302

Collins J (1984) Povrezhdeniye materialov v konstruktziyah. Analiz. Predskazaniye. Predotvrasheniye (in Russian). M: Mir

Eremeyev VA, Skrzat A, Stachowicz F (2016) On FEM evaluation of stress concentration in micropolar elastic materials. Nanoscience and Technology: An International Journal 7(4)

Giorgio I, Andreaus U, Scerrato D, dell'Isola F (2016) A visco-poroelastic model of functional adaptation in bones reconstructed with bio-resorbable materials. Biomechanics and modeling in mechanobiology 15(5):1325-1343

Hassan T, Taleb L, Krishna S (2008) Influence of non-proportional loading on ratcheting responses and simulations by two recent cyclic plasticity models. International Journal of Plasticity 24(10):1863-1889

Huang ZY, Chaboche JL, Wang QY, Wagner D, Bathias C (2014) Effect of dynamic strain aging on isotropic hardening in low cycle fatigue for carbon manganese steel. Materials Science and Engineering: A 589:34-40

Jiang Y, Zhang J (2008) Benchmark experiments and characteristic cyclic plasticity deformation. International Journal of Plasticity 24(9):1481-1515 
Korotkikh YG (1985) Opisaniye protsessov nakopleniya povrezhdeniy materiala pri neizotermicheskom vyazkoplasticheskom deformirovanii (in Russian). Problemy prochnosti 1:18-23

Lemaitre J (1985) Kontinualnaya model povrezhdeniya, ispolzuemaya dlya rascheta razrusheniya plastichnykh materialov (in Russian). Trudy Amer Ob-va inzh-meh Ser D Teoret Osnovy inzh Raschetov 107(1):90-98

Lemba (1978) Sisebottom plastichnost pri cyklicheskim nagruzhenii po neproportsionalnym traektoriyam (in Russian). Teoreticheskiye osnovy inzhenernykh raschetov 100(1):108-126

Mackenzie J (1950) The elastic constants of a solid containing spherical holes. Proceedings of the Physical Society Section B 63(1):2

Makdauel (1985) Eksperimentalnoye izuchenie struktury opredelyayushih uravneniy dlya neproportsionalnoy cyklicheskoy plastichnosti (in Russian). Teoreticheskiye osnovy inzhenernykh raschetov 107(4):98-111

Mazière M, Forest S (2015) Strain gradient plasticity modeling and finite element simulation of lüders band formation and propagation. Continuum Mechanics and Thermodynamics 27(12):83-104

Miehe C, Göktepe S, Diez JM (2009) Finite viscoplasticity of amorphous glassy polymers in the logarithmic strain space. International Journal of Solids and Structures 46(1):181-202

Misra A, Poorsolhjouy P (2015) Granular micromechanics model for damage and plasticity of cementitious materials based upon thermomechanics. Mathematics and Mechanics of Solids $\mathrm{p}$ 1081286515576821

Mitenkov AM, Kaydalov VB, Korotkikh YG (2007) Metody obosnovaniya resursa yaeu (in Russian). Mashinostroyeniye $\mathrm{p} 445$

Mitenkov FM, Volkov IA, Igumnov LA (2015) Prikladnaya teoriya plastichnosti (in Russian). Fizmatlit p 284

Montáns FJ, Bathe KJ (2005) Computational issues in large strain elasto-plasticity: an algorithm for mixed hardening and plastic spin. International Journal for Numerical Methods in Engineering 63(2):159-196

Murakami S (1983) Sushnost mehaniki povrezhdennoy sredy i eyo prilozheniye k teorii anizotropnykh povrerzhdeniy pri polzuchesti (in Russian). TOIR 2:44-50

Ohasi, Kavai, Kaito (1985) Neuprugoye povedeniye stali 316 pri mnogoosnykh neproportsionalnykh zyklicheskikh nagruzheniyakh pri povyshennoy temperature (in Russian). Teoreticheskiye osnovy inzhenernykh raschetov 107(2):6-15

Papadopoulos P, Lu J (1998) A general framework for the numerical solution of problems in finite elasto-plasticity. Computer Methods in Applied Mechanics and Engineering 159(1-2):1-18

Papadopoulos P, Lu J (2001) On the formulation and numerical solution of problems in anisotropic finite plasticity. Computer Methods in Applied Mechanics and Engineering 190(37-38):48894910

Placidi L (2016) A variational approach for a nonlinear one-dimensional damage-elasto-plastic second-gradient continuum model. Continuum Mechanics and Thermodynamics 28(1-2):119137

Schröder J, Gruttmann F, Löblein J (2002) A simple orthotropic finite elasto-plasticity model based on generalized stress-strain measures. Computational Mechanics 30(1):48-64

Soyarslan C, Tekkaya A (2010) A damage coupled orthotropic finite plasticity model for sheet metal forming: Cdm approach. Computational Materials Science 48(1):150-165

Taleb L, Cailletaud G, Saï K (2014) Experimental and numerical analysis about the cyclic behavior of the $304 \mathrm{~L}$ and $316 \mathrm{~L}$ stainless steels at $350^{\circ} \mathrm{C}$. International Journal of Plasticity 61:32-48

Tanaka E, Murakami S, Ōoka M (1985a) Effects of plastic strain amplitudes on non-proportional cyclic plasticity. Acta Mechanica 57(3-4):167-182

Tanaka E, Murakami S, Ōoka M (1985b) Effects of strain path shapes on non-proportional cyclic plasticity. Journal of the Mechanics and Physics of Solids 33(6):559-575

Volkov IA, Igumnov LA (2017) Vvedenie v kontinualnuyu mehaniku povrezhdennoy sredy (in Russian). M: Fizmatlit p 304

Volkov IA, Korotkikh YG (2008) Uravneniya sostoyaniya vyazkouprugoplasticheskikh sred s povrezhdeniyami (in Russian). Fizmatlit p 424 